\title{
Management of Second-Hand products and their influence on buying behavior in the Covid-19 period -Eye on Tunisia-
}

\author{
${ }^{1}$ Samiha CHENAG, ${ }^{2}$ Younes ZIEITA, ${ }^{3}$ Bilel Rehalia, \\ ${ }^{1}$ High Business School-ESCT-Manouba, Tunisia \\ ${ }^{2}$ University of 8Mai 1945, Guelma, Algeria \\ ${ }^{2}$ University of Mohamed Chrif Messadia, Souk Ahras, Algeria
}

\begin{abstract}
While the textile sector has been hit hard by the Covid-19, the health crisis is also seen as "an opportunity for change". Several brands are thus entering the second-hand market by opening dedicated spaces directly in their stores. It's the new standard for brands and stores. Due to COVID-19 pandemic, we believe that the Tunisian costumer's purchasing behaviour got affected by the new governmental preventive restrictions in order to protect all the chain of workers who are supposed to deal with this kind of products and the costumers at the end the process. Therefore, Tunisians had to adopt with this new situation by using local second-hand clothes shopping internet platforms like Dabshi and Tayara... ect.

For this reason, this research aims to clarify and analyze the consumer's tendency to buy used clothes during the outbreak of the epidemic. We have designed an online survey using a mix of convenience and snowball sampling strategies. The survey conducted on 260 Tunisian consumers -most of them are women- using Smart-PLS, showed that the spread of the epidemic affected the psyche of Tunisian consumers. There are those who refrained from purchasing used secondhand clothing and there are those who did not affect the epidemic on their purchasing habits. Thus, the purchase decision is closely linked to the citizen's education and awareness level, as well as his purchasing capacity.
\end{abstract}

Key words: Secondhand; SHC, Covid-19; costumer; loyalty. 